\title{
Erratum: Vulnerability of Southern Afar pastoralists to climate variability and change, Ethiopia
}

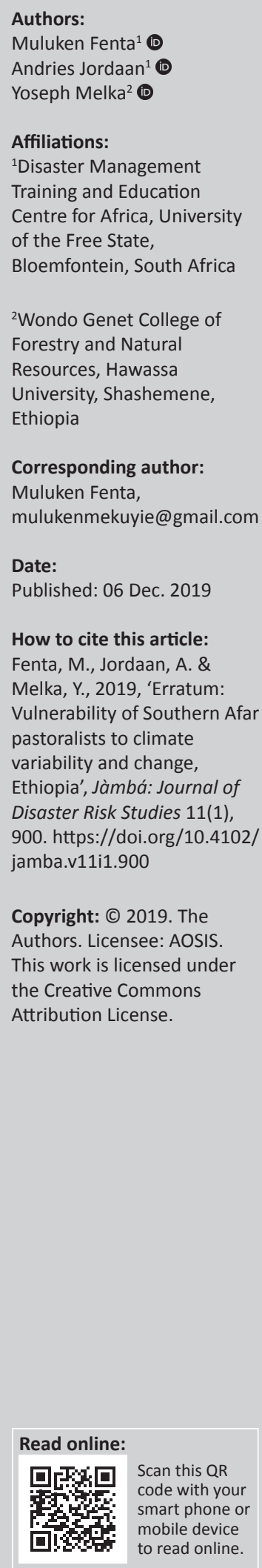

Scan this QR
code with your
smart phone or
mobile device
to read online.

In the version of this article published earlier, the date of publication reflected the incorrect year. The publication date, under the heading 'Dates', should have been 18 Apr. 2019 instead of 18 Apr. 2018.

This correction does not alter the study's findings of significance or overall interpretation of the study results. The publisher sincerely apologises for any inconvenience caused. 